\title{
A proposal to explain "covert" increases in intracranial pressure
}

\author{
Doug Hamilton, Mark Hamilton *, Alim Mitha, John Tyberg \\ From Hydrocephalus 2015 \\ Banff, Canada. 18-21 September 2015
}

\section{Introduction}

Some substantial number of unfortunate patients suffer from the symptoms and signs of elevated cerebrospinal fluid (CSF) pressure, even though pressure measured in the cerebral venous system is normal. We hypothesize that, with elevated CSF pressure, cerebral microvascular congestion may occur, even though (subdural) largevein pressure has been shown to be normal.

\section{Background}

Even with elevated CSF pressure, large-vein pressure could be normal because the large veins are "tented" open by their structural relation to the dura. However, the smaller, penetrating veins are not protected by the dura in this way so they could collapse. By this "Starling-resistor" action, venular and microvascular pressure would have to increase if flow were to continue. This increased microvascular pressure might be measured by an adaptation of cardiologists' wedge-pressure logic. (When an artery is obstructed by a catheter or by the inflation of a balloon, the pressure measured in the stationary column of blood beyond the obstruction is equal to the downstream pressure.)

\section{Hypothesis}

These concepts are illustrated in the figure. Solid lines indicate the relationships of intravascular pressure when CSF pressure is normal $(\sim 10 \mathrm{mmHg})$. Dashed lines indicate the relationships when CSF pressure is elevated $(\sim 35 \mathrm{mmHg})$. If flow is to continue, the pressure in the capillaries and in the small penetrating veins must exceed CSF pressure. However, pressure in the large "dura-strutted" veins will continue to be normal and to be governed only by right atrial pressure.

\footnotetext{
* Correspondence: mghamilton.random@gmail.com
} University of Calgary, Calgary, Canada 